Proc. of The Sixth Intl. Conf. On Advances In Economics, Social Science and Human Behaviour Study - ESSHBS 2017

Copyright (C) Institute of Research Engineers and Doctors, USA .All rights reserved.

ISBN: 978-1-63248-120-7 doi: 10.15224/ 978-1-63248-120-7-69

\title{
ANTECEDENTS OF ADOLESCENT PARENTHOOD: A STUDY OF BONDO AND NAIROBI DISTRICTS IN KENYA
}

Abstract: - The general objective of the study was to find out, compare and analyze factors of socio-cultural and socioeconomic nature that could explain the differentials in adolescent reproductive behaviour by gender and urban-rural place of residence in two districts in Kenya: Bondo and Nairobi. Nairobi represented an urban area while Bondo, a rural environment. The study was based on a sample of 533 adolescents. Of these 272 (51 percent) were females while 262 (49 percent) were males. Of the 533 informants, 296 were from Nairobi (55.5 per cent), and the remaining 273 (44.5 per cent) were from Bondo. The target populations were adolescent girls and boys, in and out of school, with and without children, in and out of marital unions. Information on adolescent reproductive behavior was obtained using interview schedules, focus group discussions guides and observations checklist.

Data obtained were analyzed using both qualitative and quantitative approaches to complement each other in explaining the individual and collective contributions of identified determinant factors. Bivariate cross tabulation analysis was used to study the association between variables, $\mathrm{X}^{2}$ was extensively used to ascertain significance levels where it was expedient to test for possible association between variables and simple logistic regression analytical technique was also used to help understand the interrelationships among selected variables. The key findings from this study indicate that adolescent parenthood is a function of an array of factors and not a single behavioural phenomenon. That parenting results from the interaction of a number of background factors (community reproductive values and policy environment) and adolescent characteristics (referred to as antecedent factors) as well as intermediate or proximate factors. The latter were found to be mediators in the process of adolescent reproductive behavior. These factors did interact in crosscutting ways to influence parenting among young people (See Conceptual Framework below).

Adolescent characteristics considered in this study were gender, place of residence, sex of the household head, number of siblings, birth order, age at first sexual debut, level of education, employment status and level of income. These factors were found to separately and independently influence adolescent reproductive behavior. Logistic regression results indicated that factors such as gender, level of education, employment status and parental socioeconomic status in their own right, were found to be significantly associated with parenting among young people. This study has also highlighted the magnitude of adolescent parenthood in terms of proximate determinants, namely: marital status, health seeking behavior, contraceptive use, coital frequency, pregnancy and abortion. Among these factors, four, namely contraceptive use and abortion were found to directly or independently influence parenthood. It was further noted that the antecedent factors did influence fertility behavior not only directly, but also through individual proximate variable as well as through a combination of these variables. In addition, the factors in the larger society or community and policies, which either support or disapprove adolescent behavior, did exert powerful additional influences on young people's reproductive behavior. Factors such as parental and community values interacted in complex ways to reinforce the influence of adolescent characteristics and proximate factors on parenthood.

The conceptual framework attached shows the direction of causality.

Key words: - Adolescent, antecedents, adolescent sexual behavior, parenthood, fertility

Mildred Jenifer Lodiaga

Department of Gender and Development Studies, Kenyatta University,Kenya 
Figure 1.

\section{SELECTED FACTORS REGARDING ADOLESCENT PARENTHOOD}

Underlying factors

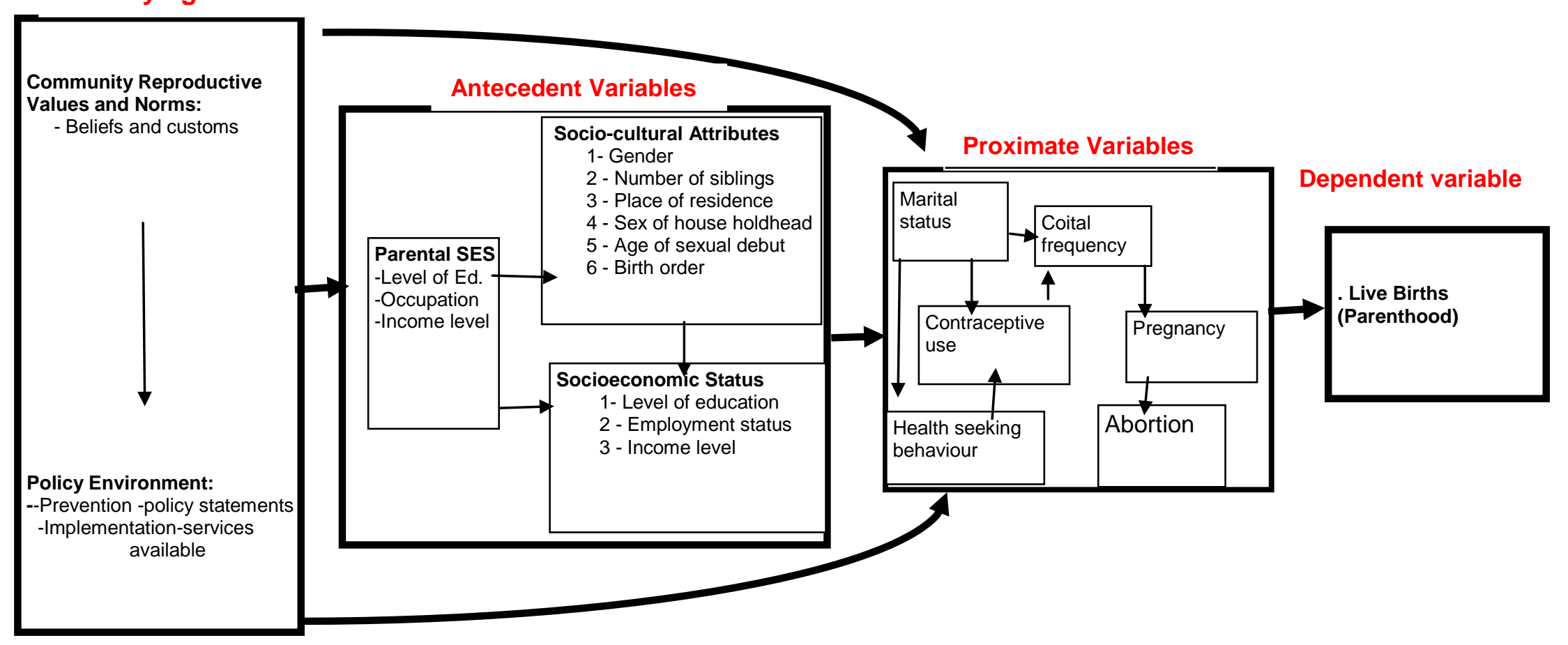

Key

Direction of Causality/Influence 